\title{
Desafíos posmodernos de la obra literaria de Juan Benet
}

Jorge Machín Lucas', The University of Winnipeg

Recibido: 6 de junio, 2015.

Aceptado: 18 noviembre, 2015.

\section{Resumen}

En este artículo se analiza una serie de cuestiones posmodernas nada o poco estudiadas en la obra del novelista y ensayista Juan Benet (1927-1993). Se estudia su interés por las minorías, su rechazo del valor del progreso, su uso globalizado del inglés, su tendencia hacia el fragmentarismo, el kitsch, el pastiche y el collage, su noción de distopía y de heterotopía, una deconstruida dicotomía entre razón y pasión, su rechazo de los sistemas teleológicos de conocimiento, su tendencia a mostrar una sexualidad sin amor puro, morbosa y violenta, y una violencia en general y hacia la mujer en particular.

El artículo es original y procede de un proyecto de investigación acerca de la obra de Juan Benet ante la posmodernidad, lo irracional y lo intertextual.

\section{Abstract}

\section{Post-modern challenges of the literary works of Juan Benet}

This paper analyzes a series of post-modern issues being studied very little or not at all regarding the literary work of the essay and novel writer Juan Benet (1927-1993). His interest in minorities is studied as well as his rejection of the value of progress, his globalized use of English, his tendency to fragmentism, "kitsch", "pastiche" and "collage", his notion of "distopia" and "heterotopia", a deconstructed dichotomy between reason and passion, his rejection of teleological knowledge systems, his tendency to show sexuality without pure love, morbid and violent, and a general violence towards women in particular.

The paper is original and stems from a research Project about the Works of Juan Benet in the face of post-modernism, the irrational and the intertextual.

En el presente artículo se van a explorar una serie de aspectos, tanto sincrónicos como diacrónicos, que vinculan la obra narra- tiva y ensayística de Juan Benet (1927-93) con la posmodernidad. Algunos de ellos han sido escasamente explorados y otros

1 El doctor Jorge Machín Lucas es profesor asociado de Estudios Españoles en el departamento de Lenguaje y Literatura Modernas de la Universidad de Winnipeg, Canadá. Tiene una licenciatura en Filología Hispánica de la Universidad de Barcelona y un doctorado en Literatura Española de la Universidad del Estado de Ohio. Contacto: jorgemachin@yahoo.es

Jorge Machín Lucas. Desafíos

posmodernos de la obra literaria de Juan Benet. Revista Comunicación. Año 36, vol. 24, núm. 2, julio-diciembre, 2015. Tecnológico de Costa Rica. ISSN impreso: 0379-3974 / e-ISNN: $1659-3820$

\section{PALABRAS CLAVE: \\ Juan Benet, literatura española \\ contemporánea, narración, ensayo.}

KEY WORDS:

Juan Benet, contemporary Spanish literature, narrative, essay. 
lo han sido pero desde otras ópticas y métodos. Aquí se proponen las vinculaciones de Benet con este movimiento sociohistórico, partiendo del hecho de que su obra es una reacción, consciente o inconsciente, contra los excesos del mundo capitalista y globalizado. Con su obra, Benet se opone a un mundo técnico-tecnológico, que paulatinamente se iba embotellando, cual aldea virtual. Un mundo de cultura de masas, de música pop y de información saturada, cosmopolita, materialista, realista; un mundo sistemático, consumista, hedonista, "falo(go)céntrico" y autoritario. Lo más opuesto al cronotopo de Región que el español situó tanto en el Bierzo leonés como en la tradición literaria universal, por mucho que lo hispanizara el prestigioso crítico Gullón (1973).

En ese espacio-tiempo ficticio, muchas veces incardinado en la España de la Guerra Civil española de 1936 a 1939, Benet muestra su contrariedad contra toda teleología o búsqueda de causas finales, de dar grandes explicaciones a los grandes misterios de la vida, del origen, de la creación y del destino humanos en el mundo y en el universo. Nada más contrario a su forma mentis es el pretender ofrecer verdades absolutas: su novela es una de incertidumbre, de indeterminación, de vacíos argumentales y semióticos que el lector ha de rellenar con su imaginación modelada por su experiencia.

Benet quiere apartarse de la imperante y monolítica tradición realista, naturalista y costumbrista y de todo intento de denuncia, de testimonio o de compromiso social. Cree que el arte comprometido no fructifica ni pasa a la posteridad, pues lo que lo hace inmortal es el estilo, no el argumento, producto de combinaciones y permutaciones de los mismos temas de siempre. Este arte usurpa el terreno de las arrogantes e imperfectas ciencias, política, sociología y economía, en vez de adentrarse en el suyo propio: aquel en el que se ha creado una nueva realidad partiendo de una expansión o reversión epistemológica de lo real y racional hacia sus caras no perceptibles, más allá del alcance de nuestros limitados sentidos. Para él, el del arte tiene que ser el espacio de lo irreal e irracional. Lo representa con su atrezzo o puesta en escena de orden mítico, con sus fantasmagorías y panteísmos que engloban la acción del ser humano, la naturaleza y lo divino. Lo hace con poca retroalimentación anclada en la sociología o en la historia que no sea la que le dan los intertextos o ciertas experiencias personales que tan solo sirven de base al andamiaje de la ficción.

Desde un análisis heurístico de tipo sociohistórico y cultural de la época, este proceso de absorción ideológica se produjo, tanto por una necesidad ontológica de explicarse un mundo en decadencia -el de la Guerra Civil, el de la postguerra y el de la dictadura franquista hasta 1975- como por un proceso natural de ósmosis con otros autores o movimientos, resuelto mediante la intertextualidad (concepto desarrollado por Julia Kristeva). Benet realiza una crítica a su historia y, ante todo, a la de la literatura mediante la parodia de discursos previos, lo que es un cierto kitsch o pastiche de elementos palimpsésticos que ayudaron a germinar el humus de su imaginación. Son diálogos supraliterarios con la tradición de las letras y de las ideas en los que deforma y parodia a los maestros. La literatura de Benet procede de una palimpséstica circulación de ideas más allá del mero comparativismo.

En este caldo de cultivo de ética y de estética irracional, los siguientes novelistas fueron los clásicos literarios que permearon a Benet y que acrisolaron las innovaciones formales y temáticas del siglo XX. Se dejó germinar más por los grandes tótems de la cultura universal que por los de la hispana. Autores de renombre como Marcel Proust, con sus largos arabescos, o William Faulkner y su Yoknapatawpha County y su galería de locos y violentos, o Franz Kafka y sus angustiosos microcosmos entre lo real y lo filtrado y lo creado por la conciencia. También le influyeron los grandes historiadores de la antigüedad grecolatina, como Jenofonte, Plutarco, Tácito o Amiano Marcelino. E incluso narradores como Euclides da Cunha -subversor del positivismo desde dentro de sus filas al realzar el valor del estilo en el recuento periodístico pasado a novela-, filósofos como Henri Bergson -con su noción de la durée, o tiempo de la conciencia opuesto al cronológico-, Friedrich Nietzsche -con su defensa del irracionalismo y del valor del estilo-, e incluso un antropólogo como Sir James George Frazer y los mitos que había recogido. También se encuentran al trasluz de sus páginas las huellas de narradores no necesariamente realistas como Joseph Conrad, Herman Melville o Henry James, cultivadores 
de estilos, de mundos y de acciones sorprendentes, entre muchos otros.

Es complejo pretender hacer una cartografía del mundo literario posmoderno, tanto en lo global como en lo hispánico en particular, pero se pueden destacar ciertas ideas base, aplicables a la literatura benetiana. Algunas las acepta y otras las subvierte. En este artículo se discutirán varias vertebrales, más otras de carácter secundario y sus consecuencias. La primera afirma que la posmodernidad es la expresión de un tiempo en el que lo natural ha desaparecido del arte y de la tecnología por completo (Jameson, 1991), algo que avala la literatura benetiana, donde lo intertextual y el estilo superan con creces el valor aledaño de la realidad y del argumento.

La segunda señala que la posmodernidad es un periodo cultural caracterizado por la "indetermanencia", es decir, la combinación de indeterminación acerca del sentido de lo vivido y de lo que se vivirá y de inmanencia o de penetración en el centro del ser (Hassan, 1987), típica de la obra benetiana que indaga en la conciencia frustrada y fracturada de sus personajes.

Esta obra se caracteriza también por los vacíos en la trama, por la indeterminación y por la incertidumbre en espacios que son más de conciencia que físicos. La artificiosa conciencia de los personajes benetianos está distorsionada por un sentido amargo del fracaso personal. Es la "psique" humana más desgarrada y torturada. Benet no se detiene apenas en apreciaciones racionales, con una galería de imágenes y de posibles conversaciones imaginadas que se impone sobre las referencias espaciales o geográficas y sobre toda deixis literaria. Una conciencia más intelectualizada en lo irracional, la engañosa y traicionera de los seres humanos, es la que tamiza arbitrariamente y la que desvirtúa el material de lo vivido para ayudar a sobrevivir a los personajes benetianos que nunca alcanzan unos mínimos de pena y de sentimiento de culpa. Esto hace, por momentos, de su novela un tratado ensayístico a lo Thomas Mann.

La tercera reza que la posmodernidad es expresión del sublime o de lo inefable (Lyotard, 1993). Benet trata de revelarlo a través del estilo, de la divagación o especulación ensayística y del análisis de las con- ciencias de sus personajes. Es la era de los excesos hedonistas y del análisis de los defectos represivos de ese "proceso de personalización" y de "singularidad subjetiva", apreciables en el narcisismo, en el sexo y en la satisfacción de los impulsos más primarios o más dañados y dañinos (Lipovetsky, 2010). Es la del cool sex, la de las "relaciones libres", la del sexo sin "tensión emocional" ni "intensidades afectivas", la de la "violencia espectacular" (Lipovetsky, 2010, pp. 76-77). En Benet no es un proceso urbano de desarrollo del ego paralelo al de la ciencia y al de la tecnología. En su obra, este descubrimiento y explotación de la "ipseidad" y de la sexualidad se produce en tiempos de guerra y de destrucción o en ambientes decadentes y represores que coartan el libre impulso personal. Benet habla más de restricciones y de represiones que de liberaciones o de satisfacciones de los deseos y de los sentidos. De estos puntos y de otros aspectos y matices críticos más centrados en la figura intelectual y novelística de Benet dimanarán las venideras ideas de este análisis.

Su obra, de carácter experimental, anatomía del ser, de la palabra, de la literatura y de la historia, es una correa de transmisión de ideas narrativas y de toda una era tan ideológica, la de la posmodernidad, como artística, formal o estructural, la del posmodernismo. Las intelectualizadas novelas de Benet, metanovelísticas y autorreflexivas, que se apartan mayoritariamente de los "géneros menores", están casi por completo desvinculadas del referente realista tan tradicional en las letras hispánicas desde la Edad Media, el cual tiene su mayor estímulo desde El lazarillo de Tormes (Anónima) y la novela cervantina. Versan sobre la memoria, el tiempo, la razón y la pasión, lo irracional, la sexualidad y la incertidumbre en sus niveles macro y supraliterarios. También revelan cuestiones de capital importancia relacionadas con el sustrato nacional, con la identidad personal, con el estilo, con la densidad intelectual, con la orientación sexual y con la intertextualidad. Ellas se integran dentro de una estética e ideología tales que, mientras niegan el discurso figurativo con la estructura polifónica y multigenérica, tratan de expandir semióticamente su área de conocimiento hacia una realidad existente y desconocida más allá de lo racional, en el terreno que situamos en los infra o ultrasonidos, en lo abstracto, en lo irreal, en lo irracional, en la 
inmaterialidad de la materia. Es el terreno que precede y que continúa lo que podemos percibir: lo exotérico.

El discurso benetiano, así pues, serpentea por una dicción y por una estructuración narratológica que ya son autorreferenciales ya que expresan el mundo de lo esotérico, lo que el autor de Región Ilama "las zonas de sombras" del saber. Ello se expresa con el elevado y rupturista estilo benetiano. Este es tanto de origen épico -importado a través del relato periodístico narrativizado de Da Cunha en Os Sertões de 1902 sobre la rebelión en Brasil a finales del XIX de Antonio Conselheiro en la Guerra de Canudos- como trágico -filtrado por Nietzsche desde El nacimiento de la tragedia de 1872-. Este estilo está caracterizado por la falta de "decorum", ya que todos sus personajes hablan de manera similar, en un estilo intelectual y grandilocuente que combina lo narrativo, lo poético, lo filosófico-especulativo, lo disertativo, lo científico y lo humorístico y sarcástico. En pocas palabras, es el mismo autor, o el hombre que él quisiera haber sido, el que habla a través de ellos.

El cronotopo o articulación espacio-temporal benetiana, centrado en la comarca ficticia de Región, en el mítico bosque de Mantua, en su capital y en casas aisladas del mundo exterior, se sitúa en un presente congelado y maldito por un pasado regido por fuerzas inmemoriales en forma de atávica tradición que está condenado a la repetición. Lo que lo hace novedoso es que al ser autorreferencial es inmanente, una proyección de las conciencias regionatas que claman por sus fracasos. Refleja las conciencias fracturadas y bloqueadas de sus personajes que lo distorsionan y que, influidas por Nietzsche (2009) desde el mencionado libro El nacimiento de la tragedia, se debaten en un deseo incapaz de ser llevado a cabo entre actitudes que se identifican con lo apolíneo, lo espiritual, la pasión, y con lo dionisiaco, lo sensual, la acción, tal y como he demostrado en un artículo reciente (Machín Lucas, 2015, pp. 345-8).

Benet se inclina por ambientes o casas rurales en una tierra marcada por una fantaseada Guerra Civil española, que es culminación de un determinismo y de una fatalidad inmemoriales. En esas casas cerradas, las obsesivas y enfermizas conciencias de unos personajes en actitud de espera hacia la muerte y ha- cia la nada encuentran un espacio propicio para la inescapable circularidad en espiral de sus divagaciones que transforman lo vivido y lo circundante para luego fijarla, cristalizarla y acrisolarla progresivamente. Estas mentes están motivadas por un fatalismo regionato que es para Benet una diversión más brutal que las lágrimas para los solitarios que allí viven o, mejor dicho, que allí mueren en vida. Son producto de su aislamiento social, tal y como se expresa en Volverás a Región (1967). Esa depurada Región hacia la distopía y la heterotopía del "otro" perdedor, del subalterno, espacio del no hegemónico foucaultiano, de lo percibido por cuerpos y mentes malsanos y torturados por la lucha de clases y por la historia, procede tanto de la comarca leonesa del Bierzo como de los experimentos de William Faulkner con su estadounidense Yoknapatawpha County. Este fue un condado ficticio situado en el "Deep South" americano inventado por el premio Nobel estadounidense. Asimismo, conviene no ignorar la importancia de Euclides da Cunha y de Malcolm Lowry en la articulación del cronotopo regionato con sus depurados Canudos, en el Sertão brasileño, y Cuernavaca, en México, respectivamente.

Este mundo decadente regionato está regido no solo por leyes inmemoriales sino también, metaliterariamente, por códigos internos narratológicos, temáticos e ideológicos anclados en la tradición más rupturista del siglo XX. Esta parte de Joyce y de Faulkner con rasgos heredados como son los siguientes: autorreferencialidad, metaliteratura, relativismo gnoseológico, monólogos, trasvases de narradores sin previo aviso, narradores poliédricos, discursos multigenéricos, multiestilísticos, polifónicos, pluriperspectivistas, Grand Style, falta de "decorum", temas no bucólicos ni idealizantes, violencia, decadencia, locura, investigaciones acerca del tiempo, de la palabra, de la atomización del ser y del fragmentarismo de la realidad percibida y de la no percibida aunque intuida.

Por poner un par de ejemplos de esta apuesta de literatura no idealista y bastante pesimista, aunque con deseos por momentos místicos y redentores que se sabe que son imposibles de conseguir como he demostrado (Machín Lucas, 2015, pp. 9-10), se tratan las tempestuosas y descarnadas relaciones de seres amargados o insatisfechos que no ocultan un fondo 
de carácter sadomasoquista. O también la obra de Benet, en muchos momentos, es un muestrario de obsesiones y de aberraciones que pretenden demostrar el egoísmo no altruista y la imperfección humana rayana en el sadomasoquismo. Hay violencia, aunque no es explotada de manera efectista. Se muestran más sus efectos psicológicos y sus derivaciones intelectuales que su imposición, tanto en la guerra, como en el coito o en la ausencia de este. Todo es tamizado por la profundización que el autor realiza en la mente humana, de la que esos temas son excusa para realizar pensamientos divergentes a lo comúnmente aceptado por una sociedad hipócritamente biempensante.

Todo esto en conjunto pretende levantar acta catastral de una sociedad y hacer una radiografía de sujetos posmodernos, personajes al borde del vacío personal e identitario, en un mundo que se ha ido saturando tanto de ideas y de materiales para consumir, y que ha llevado a los seres humanos, frustrados y alienados, a buscar la excitación y la novedad en sus cuerpos mediante la cara más primitiva del hedonismo. Ellos confunden el placer con una falsa y morbosa espiritualidad narcisista en un presente congelado de irresoluciones vitales. No hay otra diversión posible en un mundo tan hostil. Ya se han desviado todos del placer suave y agradable. Son el eros, la violencia y el dolor, tanto físico como psicológico, los que conducen a los personajes a una locura, a una (auto) destrucción o a una muerte programadas por sus seres tanto como por la terrible historia de España. Por añadidura, están condenados por un presente aciago, por un futuro condenado a la repetición de lo malo, por las ominosas fuerzas inmemoriales del bosque de Mantua y por su fiero y terne guardián, el más que centenario y mítico Numa, un intertexto de origen clásico sacado de Plutarco en su obra Bioi Parallelloi (Vidas paralelas) y de Sir James George Frazer en The Golden Bough (La rama dorada).

Como se ve, la psicología y los temas de resonancias universales son importantes. La escasez de datos y de detalles en la espacialización de sus novelas, si exceptuamos el levantamiento topográfico que hace al principio de Volverás a Región (1996), se resuelve en una penetración inmanente en sus personajes. Ellos están interconectados con su propia identidad fracturada, entre sí y con la naturaleza mítica, mís- tica, épica y trágica del mundo regionato, así como con la propia historia de la literatura. Por ejemplo, los dos protagonistas de Volverás a Región, Marré Gamallo y el doctor Sebastián, se minimizan entre ellos en su diálogo de sordos, que en realidad vienen a ser dos monólogos. Son futura carnaza para Numa, el guardián del bosque de Mantua, y son víctimas y verdugos de sus actos más primitivos que les llevan a la búsqueda fallida del amor y de la sexualidad plena por parte de ella y a la de la supervivencia tras el fracaso humano y amoroso por parte de él.

Benet además, retrata el flujo depurado de sus mentes y de sus psicologías desde sus pasados. Sus pensamientos y sus instintos quedan al descubierto para llegar así a esas conclusiones generales que subyacen en la estructura profunda de su obra y que remiten más a ella misma, a lo metaliterario, que a cualquier tratado o teoría psicológica o filosófica. Benet se posiciona frente al sexo y a la vida con conciencia de hegemónico desde su punto de vista heterosexual, el cual difícilmente puede socavar cualquier análisis psicoanalítico de género o de teoría queer. No se advierte de manera evidente ningún sentimiento "homoerótico" subyacente en ninguno de sus personajes o incluso en el mismo autor.

Por consiguiente, las líneas medulares de esta interrelación aludida entre hombre, mundo, ideología, historia, mito y literatura nos llevan a ocho puntos emblemáticos para rivalizar en su personal opción de posmodernidad. Algunos de ellos no han sido debatidos en exceso todavía y otros lo van a ser desde un nuevo prisma. Ellos son:

a. El rol de las minorías en su obra.

b. El uso y valor del estilo y del stream of consciousness.

c. La tendencia hacia el kitsch, el pastiche y el COllage así como hacia lo multigenérico y multidisciplinar.

d. La creación y articulación en el cronotopo entre espacio-temporal y de conciencia de una distopía y de una heterotopía sobre una posible utopía.

e. El debate entre razón y pasión. 
f. El rechazo de toda teleología epistemológica y, por extensión, gubernamental.

g. El tema de la sexualidad y, finalmente,

h. el tema de la violencia de género.

\section{EL ROL DE LAS MINORÍAS EN SU OBRA}

Aparte de su adscripción al pensamiento de lo que tradicionalmente se ha considerado como de minorías de poder o marginados, como discapacitados psíquicos -locos, obsesivos, recluidos, deficientes mentales, agresivos o visionarios-, como puede apreciarse en sus novelas, Benet rechaza también el valor del progreso. Muestra a personajes antiheroicos, perdedores, semienloquecidos o alienados, freaks que intentan apartarse del materialismo y de la competición salvaje del mundo exterior para encontrarse consigo mismos. Esto se ve en una omnipresente alienación o enajenación típica en algunas de sus obras. Se canaliza y plasma mediante el arte, la violencia y el sexo morboso. Empero, se muestran intelectualizadas y por eso renuncia al "decorum", para someter esas voces a una unificación y a un análisis intelectual y discursivo. Como se ha anticipado previamente sobre Volverás a Región (1996), Marré Gamallo, mujer víctima de abusos físicos y psicológicos con cierto síndrome de Estocolmo, trata de buscar infructuosamente la plenitud sexual que le robaron episodios de coyunda sexual insatisfactoria, mientras que el doctor Daniel Sebastián vive recluido en su casa y en sus obsesiones de lo que pudo conseguir y no logró en el amor, lleno de miedo hacia el mundo real y social y amargado por los recuerdos de sus irresoluciones sexuales, mientras cuida a un niño autista que habrá de acabar con sus días. O, por poner otro ejemplo, el de Cayetano Corral en Una meditación (1970) que, tras ser abandonado por la lúbrica Leo Titelácer para esta abandonarse a los brazos del mujeriego Carlos Bonaval, vive en un chamizo obsesionado con el perfeccionamiento de un reloj que se acabará activando espontáneamente para marcar el compás de espera hacia la destrucción del tiempo congelado de Región. En esta temporalidad semicongelada, los personajes benetianos parecen estar maniatados eternamente por unas fuerzas inmemoriales de la historia española que controlan la zona regionata desde siempre y para siempre.

\section{EL USO Y VALOR DEL ESTILO Y DEL STREAM OF CONSCIOUSNESS}

En cuanto al estilo, la crítica ha observado en la obra benetiana un intento de recuperar el Grand Style de manera depurada y estética, incluso dentro del Stream of consciousness. Aparte, Benet, cosmopolita y anglófilo irredento, que llegó a menoscabar el valor de su propia cultura hispánica en favor del mundo anglosajón, usa un muy discutible inglés en la cuarta de sus catorce fábulas, en su artículo "A Short Biographia Literaria", y en alguna parte de sus textos, como se aprecia en un comentario marginal de Un viaje de invierno (1989, p. 232). El inglés es la lengua de la modernidad y de la posmodernidad, del mundo capitalista imperante, de la gran cultura inglesa y americana y de su Grand Style. Es una lengua de internacionalización y de globalización frente a las estrecheces de lo local, marcado por una dictadura opresiva y castradora culturalmente, como fue la de Franco. Esta lengua fue una manera de dar un criterio de autoridad y de distinción cultural a su historia en un ambiente cultural español que Benet reputaba como mediocre y corto de miras.

De hecho, este escritor relaciona esta lengua con lo más selecto de la literatura anglosajona, mientras que la opone a la que él considera como rancia tradición ibérica filorrealista, filocostumbrista y filonaturalista. Aparte, al usar esporádicamente el inglés, Benet pretende despertar el interés hacia otras literaturas, como son las de sus admirados e innovadores intertextos William Faulkner, Joseph Conrad, Hermann Melville o Henry James, entre otros, frente al -para él- soporífero patriarcado realista decimonónico de don Benito Pérez Galdós. Este fue un novelista epítome de la tradición peninsular más retrógrada y reaccionaria en lo formal. De acuerdo con el narrador de Región, realizaba tan solo y como sus homólogos franceses Balzac, Stendhal o Zola y en menor medida como Flaubert, un "proyecto catastral" sin pretensiones de hacer "progresar o afinar las artes narrativas" (Benet, 1997). Y así sucedía también con todos sus seguidores españoles del siglo XX, los del realismo social de posguerra. 


\section{La tendencia hacia el kitsch, el pastiche y el collage así como hacia lo multigenérico y multidisciplinar}

La forma técnica que Benet usa es similar al kitsch, al pastiche o al collage multigenérico e intertextual. Es una manera sincrética de abrir nuevas líneas de significación por interacción de géneros, de voces narrativas y de voces del pasado, que se mueven en estructura de tesis, antítesis y síntesis, opuestas a las de la tradición realista pura. Se aprecia de este modo una yuxtaposición de lenguajes en sus novelas que oscilan entre lo narrativo, lo poético, lo dramático y lo disertativo así como entre los tonos épico, mitológico, místico y dramático. Su obra narrativa es todo un caleidoscopio multigenérico, un inventario lingüístico y temático. Ello muestra la posmoderna desconfianza hacia los sistemas de pensamiento cerrados e inamovibles, hacia las verdades absolutas y dogmas de fe, y hacia todos aquellos prohombres que se creen capaces de reordenar la estructuración social a su gusto.

Benet defiende un saber fragmentario, poliédrico, infinitamente ramificado. En él se produce la conjunción entre lo histórico, lo filosófico y especulativo, lo novelístico y la narración breve, lo lírico y lo esotérico como se puede apreciar en Volverás a Región (1996), entre lo narrativo y lo dramático teatral en La otra casa de Mazón (1973) o, de manera muy parecida, aunque más desarrollada que en su primera novela, entre lo más grave y solemne del discurso narrativo y lo más paródico y humorístico en Saúl ante Samuel (1994). Para ello, se añaden carteles y todo tipo de paratextos, "mottos", comentarios a pie de página, marginales o "ladillos", entre otras formas. Por poner un ejemplo de su alto valor epistemológico, De Azúa (1986), en su artículo sobre Un viaje de invierno, afirma que estos "ladillos" - que son la antítesis, el lenguaje científico-, cuando interactúan con el texto de caja o principal-que es la tesis, el lenguaje mítico- generan un tercer texto, el denominado "texto invisible" -el cual se puede considerar como la síntesis, el texto plurisignificante, lo esotérico-. El lector debe generar esto en su proceso de descodificación hermenéutica y recrearlo en su propia imaginación desde su "variable horizonte de expectativas" literarias o gnoseológicas (De Azúa, 1986, pp. 1567).

Los intertextos o palimpsestos también forman parte de este mosaico, absorbidos en cuatro pasos básicos (según Machín Lucas, 2001) si se sigue una lectura mimética y superficial: influencia, identificación, incorporación e imitación. Faulkner, Kafka o Nietzsche producen ese interesante dialogismo bakhtiniano, tal vez, directa o indirectamente, a través del espíritu posmoderno o filtrado por el cedazo de la literatura y de la intelectualidad imperantes. De los narradores, recoge su querencia por la ruptura en la narración tradicional, por lo irracional, por lo ilógico, por lo onírico, por lo violento o por la sexualidad desviada de la norma tradicional burguesa que prima la heterosexualidad y la procreación sobre la naturaleza o sobre el deseo.

De gran interés es el caso del filósofo Nietzsche, que influyó decisivamente en Benet. Fallecido en 1900, influyó sobremanera en la posmodernidad al reevaluar y poner en tela de juicio los valores tradicionales para intentar así abrir el camino a deconstruirlos y a reconstruirlos. Eso sucedió en ese periodo de crisis de la lógica del progreso materialista y tecnológico, sobre todo tras la funesta aparición de su otra cara, la destructiva, tras el bombardeo atómico estadounidense en Hiroshima y Nagasaki en 1945, y el consecuente genocidio que se produjo. Por ejemplo, se pone en tela de juicio y se deconstruye en su obra la noción estereotípica del "superhombre" (como sucede en el caso del líder militar), producto del discurso falo(go)céntrico que sigue este camino desde este esquema: Benet subvierte el estereotipo, los clichés, los tópicos, los lugares comunes, el discurso, la ideología y el discurso ideológico (machista en este caso) para llegar a una realidad subjetiva, inmanente, autorreferencial y metatextual.

El hombre benetiano está anclado física y mentalmente por sus castraciones mentales. Está regresando a sus orígenes precivilizados, con un cierto primitivismo, prototipo de complejos de inferioridad y de represiones de su adrenalina sexual. Es una manera paródica e invertida de homenajear a la figura del "superhombre" que formuló el filósofo teutón. Benet la revirtió en algunos de sus personajes principales, como sucede con el mediocre general de los nacionales Eduardo Gamallo en Volverás a Región (Benet, 1996). Este es un penoso individuo y estratega, que vence en la Guerra Civil española de 1936 a 1939 más por desunión de sus rivales y por ayuda de un "fatum" histórico, geográfico y panteísta que por mérito y talento propios. Hay indicios en los comportamientos de sus personajes de que estos se 
estructuran a través de la dialéctica entre apolíneos y dionisiacos, espirituales y sensuales, psicológicos y somáticos, pasionales y de acción o pasivos y activos como se aprecia entre la frustrada y masoquista Marré Gamallo y el semiparalizado y lleno de irresoluciones vitales doctor Daniel Sebastián en Volverás a Región (1996).

Marré, por su parte, recuerda cómo buscó satisfacer su vitalidad y su eros reprimido en diferentes relaciones mientras el doctor se encuentra inmovilizado por su propia apatía, por una abulia resultado de una gran frustración sexual. La abuela pitonisa, una especie de sibila, desde su pensamiento esotérico y profético, y el primo Simón, desde su reflexión metaliteraria, ejercen ambos de apolíneos en Saúl ante Samuel (1994) mientras juzgan las acciones y el destino trágico del antihéroe militar, el soldado Emilio Beltrán de Rodas. Hacen como hizo el profeta Samuel con el primer rey del pueblo judío, Saúl, a quien además de coronar, evaluó. También pueden proceder de Nietzsche, o del espíritu de época que le llevó a germinar esas ideas, los posicionamientos de Benet en contra del logocentrismo, del falo(go)centrismo y de los sistemas de pensamiento cerrados, así como su tratamiento del irracionalismo. En Benet esto se ve dentro de la textura ilógica argumental y en sus reflexiones en excursos y digresiones. De Nietzsche pueden venir además cierto nihilismo, la presencia de lo trágico en sus obras o la idea del violento eterno retorno hacia la muerte y el renacimiento, la destrucción y la reconstrucción. O también los sujetos descentrados ante sí mismos y ante su papel en la sociedad, en la historia y en la alteridad, la voluntad de poder de algunos de sus personajes (el general Gamallo, por ejemplo) y la de estilo, sobre todo en lo lingüístico. Básicamente, todo esto se puede detectar primordialmente desde El nacimiento de la tragedia (Nietzsche, 2009) y desde Así habló Zaratustra (Nietzsche, 2009) aunque sin duda esas influencias se extienden por el resto de obras nietzscheanas.

La creación y articulación en el cronotopo entre espacio-temporal y de conciencia de una distopíay de una heterotopía sobre una posible utopía

La obra benetiana es un ejemplo de los conceptos de distopía o sociedad ficticia indeseable y de heterotopía o lugares que están en condiciones no hegemónicas, es decir, el espacio de los subalternos o de los marginados. Este funciona con base en un triple vector:

- el del espacio regionato marcado por la fatalidad y por la Guerra Civil española,

- el del de las conciencias distorsionadas por sus personajes y

- el de la tradición literaria de la que Benet bebió.

Ni qué decir tiene que la utopía mística de volver al origen, deseada por algunos personajes, se queda tan solo en un deseo. Es un cronotopo transfigurado y especializado por unas conciencias amargadas y distorsionadas por la locura, más que uno referencialmente articulado. El espacio articulado por la novela es básicamente el de la mente desgarrada de sus personajes por traumas, por complejos o por inclinaciones genéticas o congénitas. Es un espacio literario de experimentación psicoanalítica y de catarsis personal del creador. Por su parte, la ruina, la soledad, la decadencia, la desolación, la degradación y la fatalidad geográfica, tanto física como moral, tal y como ha evidenciado Herzberger (1976), caracterizan el polimorfo universo regionato de Juan Benet.

Este también es un puro espacio obsesivo de enclaustramiento, de solipsismo, de evasión de lo real, de lo geográfico y de lo geológico, que se adentra en las más etéreas "zonas de sombras" (Benet, 1996) de la razón irracional y de la ipseidad. Si no, véase cómo la primera sección de Volverás a Región, en la que un innominado viajero recorre la comarca regionata, tan solo sirve de apoyatura telúrica, de mero atrezzo con ciertas connotaciones mágicas para introducir una discusión intelectual sin salida. En esa obra se explica por qué Marré y el doctor Sebastián están obsesionados en un diálogo que es más bien la máscara de dos purgativos monólogos de dos seres que ni se escuchan ni se comprenden entre sí ni a sí mismos. La presencia de lo no consciente y de lo onírico, del misterio y de la incertidumbre con la diseminación y recolección de leitmotivos en los argumentos y finales, también marca la articulación de ese espacio. Es la indetermanencia de la que se habló antes. Ello se ve en la aparición de deseos reprimidos y de frustraciones amorosas y eróticas, expresión de lo inefable o del sublime posmoderno anteriormente mencionado de manera intelectualizada y disertadora que 
alteran la percepción del cronotopo y que la negativizan para el lector. Los personajes principales van "en busca de su centro ontológico y psicológico", tal y como nos lo ha dejado bien claro John B. Margenot III sobre el narrador madrileño (1991, p. 85).

\section{EL DEBATE ENTRE RAZÓN Y PASIÓN}

La dicotomía o conflicto entre razón y pasión, una antinomia o dialéctica estructuralista analizada por Ken Benson acerca de Juan Benet como "dos modos de aprehender la realidad radicalmente opuestos" (1989, p. 13), es también crucial en su obra. Ambas formas se pueden ver como expresiones o sublimaciones de lo impulsivo o de lo no consciente y del espíritu animal, respectivamente. Residen en el interior de los humanos, aunque se plasman como razón, que es búsqueda de estética, de refinamiento, de desarrollo intelectual o de exploración de otras capas de realidad, tanto como pasión, que es una búsqueda de eros somático, de satisfacción de los instintos primarios, de violencia y de dolor que genere un malsano placer en los sentidos de los amantes, a veces a fuer de agresor y de agredida. Estos están enfrentados con el mundo, con su pasado y con sus propios genes. También esta división de la conciencia se puede localizar entre los personajes que se debaten entre su estéril voluntad de medrar en un mundo autorreferencial, fatalista y predeterminado y su incapacidad de encontrarse a sí mismos y de centrarse como seres sociales.

En Volverás a Región (1996), Marré Gamallo quiere revivir la pasión reprimida por "la razón impuesta (García Pérez, 1997), una "razón delincuente" a la que Benet se pregunta por qué obedecemos (Un viaje de invierno, 1989). Su interlocutor, el doctor Sebastián, se pretende erigir en la razón del derrotismo con sus análisis de la historia regionata y de las esencias del ser. Los personajes benetianos, en general, tienen un impulso rebelde para conculcar o transgredir las leyes, las normas, las reglas y los tabúes. Ese impulso es, en balde, al estar dominados por ellas, por sus prohibiciones, por las fuerzas del bosque de Mantua y por su fiero cústode, el Numa, que pretenden asegurar no solo el orden natural de este mundo autorreferencial sino también el statu quo artificial entre hegemónicos y subalternos. En Un viaje de invierno (1989), la fiesta fantasmagórica que Demetria ha de celebrar por la vuelta a casa de su hija Coré, trasuntos de la Deméter y de la Perséfone míticas, abre la llegada de la primavera tras volver la segunda de su encierro en el averno o inframundo tras su rapto por parte de Hades. Esta fiesta es una suspensión del imperio de la razón ante lo irracional del mito. Además, el caballo apersogado que piafa cerca de su casa encarna esa dialéctica al representar al instinto atado por las fuerzas sociales.

Lo irracional no es contrario a la norma o a la ley, sino que está en un campo no analizado de la realidad, según Benet (El ángel del señor abandona a Tobías, 1976). Viene a ser una ampliación o revelación epistemológica del campo de la realidad y de la lógica, a los que hemos limitado con nuestras insuficientes mentes, no completamente desarrolladas. Además, la frontera entre el yo y el mundo exterior es indefinible, inestable, y si se establece, será la de un yo recortado, tal como indica el novelista español en su artículo "La frontera del yo" (Páginas impares, 1996, p. 277). Así pues, es muy difícil distinguir entre lo subjetivo y lo objetivo, con lo que tampoco podemos ver dónde acaban lo racional y lo referencial y dónde empiezan lo irracional y lo autorreferencial. Son los reinos de la incertidumbre, del enigma, del misterio no tanto policiaco como ontológico, del ser y de su inmanencia, tal y como incide Pérez en un universo caracterizado por lo anfibológico (1984).

\section{EL RECHAZO DE TODA TELEOLOGÍA EPISTEMOLÓGICA Y, POR EXTENSIÓN, GUBERNAMENTAL}

El rechazo de sistemas cuadriculados y dogmáticos de conocimiento, ya se ha discutido en su obra de incertidumbre. Se cuestiona así el papel de lo gubernamental como teleología o causa final, perfecta y única para la búsqueda del orden, y más aún en el caso de un poder dictatorial o autoritario, sobre todo del de la ultraderecha católica del general Francisco Franco (1939-75) en España. Benet invierte el modelo de Jenofonte en su Anabasis (1993), el cual muestra, desde el compromiso con su historia, desde la parcialidad y desde la no neutralidad de su visión histórica, la batalla de Cunaxa entre Ciro el joven y Artajerjes II y sus consecuencias con pretensiones de realismo y de globalidad. El del madrileño es un rechazo del status quo según Margenot III (1991), sobre todo del 
que le tocó vivir en su infancia o adolescencia en lo político y en lo cultural, momentos formativos en los que ciertas experiencias traumáticas son difíciles de asimilar y de digerir. La adolescencia viene a ser un momento de energía que clama por la libertad y se resiste a ser reprimido por las normas y reglas sociales, sobre todo si son impuestas.

En Benet, el dictador en persona no acaba de aparecer en su fantasioso mundo de ficción, a pesar de su predilección por el género historiográfico clásico, y aunque se pueda intuir de manera vaga en la mítica figura del Numa de Volverás a Región (1996). Este es un personaje inmortal y simbólico de esa tensión entre razón y pasión que garantiza que nadie viole el bosque sagrado de Mantua y que nadie salga por segunda vez del microcosmos de Región, encarnación reducida de España y del mundo entero. El Numa puede encarnarlo de manera indirecta y sin nombrarlo en su última gran obra del ciclo regionato titulada Herrumbrosas lanzas (1998) dividida en tres volúmenes. No obstante, lo ideológico adquiere una importancia muy secundaria (prácticamente nula en Benet), lo que demuestra su gran personalidad literaria como creador de un mundo de ficción autónomo y consciente de sí mismo, tal vez haciendo bueno lo que una vez dijo Althusser: "[i]deology has little to do with consciousness" (1996, p. 233).

\section{EL TEMA DE LA SEXUALIDAD}

Los temas de una sexualidad y de un sexismo abiertos, sin tapujos, sin amor, sin sentimientos sinceros ni estables, puramente carnal o pasional, inmoral, impulsivo y agresivo, cobran también gran importancia en sus obras. Ratifican las ideas acerca del sexo liberado, sin amor y a veces violento que hay en este periodo como se vio en Lipovetsky (2010). Es el estaIlido tras una gran represión social, frente a una lucha contra la entropía de las formas. Es la subversión del discurso falo(go)céntrico imperante, de desorden sexual, de Edipos, de patologías psíquicas y de socio y psicopatías. La obsesión por la virilidad y por la impotencia, por el deseo y por la represión es notoria. Se trata del puro deseo de poder llevado al cuerpo. $\mathrm{O}$ la sexualidad más narcisista y abyecta a la que llevan el dolor, la frustración y la locura genética y congénita, toda una vesania humana.
Sexo morboso, plasmación de una neurosis, de la sumisión del ser hacia otros seres, de las relaciones perversas, del sadomasoquismo, de la esclavitud y del martirio. Benet hace lo mismo con esa fuerza o instinto primario coartado por una maldición inmemorial de orden esotérico e histórico. Los personajes benetianos casi nunca llegan a poder culminar la belleza del amor carnal y sentimental ni de la erótica. Este impulso es canalizado y sublimado por un puro onanismo mental y casi solipsista, desvinculado de cualquier deseo de armonía ni de orden social. Se busca un análisis de la esencia de la mujer degradada intelectual y humanamente, a veces como objeto sexual, por un mundo de machos sedientos de poder y de fornicación, de violencias instintivas, de posesiones y de triángulos amorosos, o, en otros casos, a través de la figura de una mujer esclavizada por un infausto que la restringe a las tareas familiares y domésticas. Una mujer que trata de escapar en balde de las fuerzas tiránicas de la sociedad biempensante.

Para Benet, el sexo como afirmación de poder frente a una sociedad y a una genética constrictivas debe replicar a la razón como se aprecia en un comentario marginal de Un viaje de invierno (1989). Esa razón es la estatuida por el Estado, por la moral más retrógrada y por unas fuerzas invisibles que la representan desde el inicio de los tiempos. El sexo, así pues, debería constituirse en un modo de liberación personal que, lamentablemente, nunca llega a producirse en sus pesimistas novelas, algo detectable ante la falta de respuestas buscadas por Marré para dar sentido a su desarraigada vida y a su identidad personal en Volverás a Región según Compitello (1998). Estamos para Cabrera ante toda una "sinfonía del desespero" (1998, p. 82).

En conclusión, para Juan Benet el sexo es más evasión física o mental que una auténtica reacción frente a las normas sociales. No hay entropía ni disolución de las reglas que han sido consensuadas y aceptadas, muchas veces con hipocresía, por el común de las gentes. Hay rebeldía pero no un intento serio de revolución. Son gestos fútiles, vanos y estériles ante los dictados omnímodos de una tradición que pretende preservar el orden de hegemonías no constituidas necesariamente por un pensamiento democrático o por el talento de sus élites, sino por los vencedores en las luchas por el poder, por sus descendientes y por 
otros seres humanos de sentido común acomodaticio y narcisista. Teniendo en cuenta las ideas de este mismo filósofo, Benet está situado en la era del vacío, una posmodernidad caracterizada por una falta de proyectos sociohistóricos, suplida o compensada por una afirmación individualista de mera supervivencia y búsqueda del triunfo personal y por una negación derrotista que desconfía de la validez de los grandes sistemas de pensamiento, ideológicos o políticos.

Este universo literario es expresión de un mundo posmoderno, desnaturalizado como ya se vio en Jameson (1991), que quiere volver a lo más natural a través de la libre y plena sexualidad. Se produce esto de manera estéril, onanista y agresiva o a través de la rememoración frustrada, ataráxica y abúlica en el caso de Benet, al no haber podido conseguir sus personajes culminarla satisfactoriamente. Es una crónica de fracasos colectivos, personales y sexuales al intentar reactivar la pasión en un mundo gobernado por los excesos y por la cara negativa, la más destructiva, del materialismo, de la tecnología, del hedonismo y del consumismo.

\section{EL TEMA DE LA VIOLENCIA DE GÉNERO}

Derivado de lo anterior, otro tema de gran importancia es el de la violencia en general y, sobre todo, el del trato -o maltrato- a la mujer, degradada y denigrada por parte de hombres resentidos y amargados que soñaban con la gloriosa épica de ser grandes ciudadanos o soldados y acabaron frustrados, encerrados en una prosaica habitación apartada y oscura de su casa. Ellos descargan su adrenalina y su rabia sobre los más débiles pero no se atreven ante los más fuertes. Tal violencia puede ser emocional, verbal, física o sexual. Son los contrasentidos de una sociedad falo(go)céntrica y de su destino, además de unos hombres determinados o por la genética o por defectos congénitos en su personalidad, o incluso por sus contextos. Estamos ante un discurso estereotípico de la representación de la mujer, como mero objeto de especulación psicológica o como mero objeto sexual, aprovechado para discutir intelectualmente, que se trata de deconstruir al darles papeles centrales y al denunciar su desgraciada situación. Su origen es sociológico, psicológico e intertextual. Por poner un ejemplo, es un tema profusamente tratado que está presente en las novelas de su admirado William Faulkner (1897-1962).

La mente de los personajes benetianos es un constructo artificial implantado por el falo(go)centrismo sociopolítico y discursivo que hereda y rediseña. La tradición lo trae lleno de aporías o de contradicciones lógicas irresolubles entre la teoría, la ley y la praxis en cuanto a los derechos del individuo y de la mujer, en especial que son equilibradas por su capacidad de supervivencia, de mantener el orden impuesto y por el poder viril de los machos. Benet lo reequilibra y depura hasta convertir este tema en discusión ensayística, para tratar de sacar sus esencias universales más allá de cuestiones de género y para demostrar la culpa de todos. La mente y el falo sin argumentos son sustituidos por el argumentum baculinum, por la brutalidad física.

En esta visión muy crítica de la sociedad, lo sublime del amor deviene en abyección con la sevicia o la crueldad sin límites. Todo ello en un mundo caracterizado por su tendencia homogeneizadora de pensamiento y por su falta de respeto a la diferencia, un mundo obsesionado por la masculinidad, no solo sexual sino también por la que hay en todos los ámbitos de la sociedad, tanto en lo político como en lo económico, empresarial, cultural, educativo, de ocio deportivo... Un mundo de apariencias físicas y de representaciones ideológicamente orientadas, en el que la mujer no es respetada ni representada de acuerdo con su íntimo ser desde antes de nacer. La mujer, cuando está en su infancia, ya está siendo aprisionada bajo las expectativas de cómo deberá ser criada, de cómo deberá actuar y de cómo deberá ser tratada, de acuerdo con unos cánones patriarcales. No se la valora por lo que realmente es, sino desde la formación discursiva y preconstruida que la define desde el unidimensional discurso del falo(go) centrismo. La sociedad española de Benet es una de carácter cerril, la cual tiende meramente a valorar lo tridimensional del atractivo físico y lo no dimensional del psicológico, sin claroscuros, lo que convierte a la mujer en una víctima de las más bajas y menos edificantes pasiones.

La mujer benetiana está muy apartada del canon de la mujer bella seductora y peligrosa que encandila y hechiza en el arte, la famosa Belle dame sans merci 
(bella dama sin piedad) renacentista, del romántico John Keats (1795-1821) o de la pintura modernista prerrafaelita. Está apartada de él, no tanto por los maltratos de la violencia de género, sino porque se da más importancia a su valor intelectual y a su valor para disertar sobre la condición femenina y, por extensión, sobre la humana. Por ello, tampoco es una mujer realista. Benet, finalmente, no deconstruye hacia la izquierda los estereotipos de la mujer, pero tampoco apoya la visión tradicional de ella. Es decir, la existencia de la mujer fuera del predeterminado marco de sus novelas es denegada. Benet no logra, no quiere o desconfía de la posibilidad de deconstruir el mito de la mujer ante los poderes omnímodos de la sociedad tradicional. Se mantiene apartado del compromiso y de la tradición, que en realidad valoran la aceptación social y el triunfo más que la justicia, para adentrarse en lo ideológico, el cual depende casi exclusivamente de lo abstracto y de lo estético. La mujer es una excusa para hacer gala de un estilo de escritura y para elucubrar sobre la naturaleza y condición humana. En Benet no hay mecanismos de repetición sociohistóricos ni estéticos. Esa es la esencia de su innovadora apuesta de posmodernidad.

La violencia hacia la mujer en general, es parte de la "[b]rutalidad del orden" (Benet, 1989, pp. 161 y 222) impuesto por los vencedores de la genética, los cuales también son perdedores en lo individual al no tener más remedio que limitarse a resarcirse de su fracaso social sobre los ya vencidos. El mundo capitalista que se refleja en estas obras no es el de los más justos, sino que es un "orden siempre infatuado" como aprecia Benet si se extraen un par de comentarios marginales de Un viaje de invierno (1989). El madrileño opone y supedita el ordo amoris (el orden del amor), al ordo tremoris (el orden del temor), el de un mundo hipócrita, de prejuicios y de intolerancias hacia el otro y de indulgencias hacia uno mismo, de máscaras y de disfraces mal puestos que esconden el vacío de la personalidad. Asimismo, distingue entre el "amor fálico" y el "amor cefálico", mientras limita el poder de un falo no erecto, impotente, como si estuviera castrado, a causa de ese mundo represivo y violento adueñado de la conciencia de los personajes. Este autor también identifica el órgano sexual masculino con la cabeza, que lamentablemente muchas veces se unen sin razones de peso.
La relación diádica entre crítico y creador y entre sadismo y masoquismo es la misma que ve de Azúa en la benetiana fiesta de Un viaje de invierno (1989) en la que el sexo y el arte preservan lo originario y ayudan al Estado a "edificar su orden y su razón" (Benet, 1989, p. 157), como es la del simplista orden falo(go)céntrico, más físico que metafísico, más material que espiritual. El arte ayuda a separar momentáneamente a los personajes de esa realidad que les oprime. Ellos buscan una escapatoria y descarga de su rabia a través de la coyunda sexual violenta. Benet, en Saúl ante Samuel (1994, p. 302) evidencia una falta de creencia en el amor y proclama que en realidad no se ama a la virtud ajena sino al deseo de subyugar. El amor es, así pues, una narcisista expansión física del ego. El mundo regionato es en suma uno de poliédricos sueños eróticos de ancestro freudiano y de culposas pesadillas de abolengo lacaniano producidos por deseos no aceptados socialmente y por la violencia, sobre todo debido a una represión sexual causada por el conservadurismo, por el falso catolicismo y por la historia contra las que se opone el novelista objeto de este estudio.

\section{CONCLUSIÓN}

En conclusión, la obra benetiana es un puro reflejo de un espíritu posmoderno e internacional superior a su contexto nacional e histórico. En ella se aprecia la deconstrucción o revisión de los dictados tradicionales en lo moral y en lo formal. Además, es un excelente análisis de la conciencia humana más desgarrada por sus más elementales pasiones y por su conflicto con la sociedad que aspira a imponer el orden y la tranquilidad con la supresión o castración de los instintos e incluso con la ley o con la violencia de estado. Este estudio ha pretendido demostrar los lazos supranacionales, sociohistóricos, culturales e ideológicos que unen no solo la obra de Benet con la universal en la segunda mitad del siglo XX sino también con las ideas y la estética occidentales y con la naturaleza humana en general. Benet es uno de los autores de la segunda mitad del siglo XX que más experimentan con nuevas fórmulas y que incluso rompen, entre las décadas de los sesentas y de los setentas, con el discurso tradicional en lo estilístico, en su ordenamiento estructural y en lo ideológico. Ha sido alentado en el mundo hispano por coetáneos 
transoceánicos de la talla de un Jorge Luis Borges, de un Julio Cortázar, de un Gabriel García Márquez o de un Mario Vargas Llosa en Latinoamérica, y de un Luis Martín Santos, de los hermanos Juan y Luis Goytisolo o de un José María Guelbenzu en España. Es la demostración palmaria de la indiscutible vitalidad de una literatura en lengua española que aprende de, trasciende y mejora sus insignes modelos intertextuales de otras lenguas.

\section{REFERENCIAS BIBLIOGRÁFICAS}

Althusser, L. (1969). For Marx. Ben Brewster (Trans.). London: Penguin.

Bakhtin, M. M. (1981). The Dialogic Imagination. Four Essays. M. Holquist (Ed.). C. Emerson and M. Holquist (Trans). Austin: University of Texas Press.

Benet, J. (1970). Reflexiones sobre Galdós. Cuadernos para el Diálogo XXIII, Extraordinario, pp. 13-15.

Benet, J. (1970). Una meditación. Barcelona: Seix Barral.

Benet, J. (1973). La otra casa de Mazón. Barcelona: Seix Barral.

Benet, J. (1976). El ángel del señor abandona a Tobías. Barcelona: La Gaya Ciencia.

Benet, J. (1981). La novela en la España de hoy (1980). En La moviola de Eurípides y otros ensayos (pp. 23-30). Madrid: Taurus.

Benet, J. (1982). Sobre la incertidumbre. Barcelona: Ariel.

Benet, J. (1989). Un viaje de invierno. D. Martínez Torrón (Ed.). Madrid: Cátedra.

Benet, J. (1994). En la penumbra. Madrid: Santillana (Alfaguara).

Benet, J. (1994). Saúl ante Samuel. J. B. Margenot III (Ed.). Madrid: Cátedra.

Benet, J. (1996). Volverás a Región. V. García de la Concha (Intr.). Barcelona: Destino.

Benet, J. (1996). Páginas impares. Madrid: Santillana (Alfaguara).

Benet, J. (1997). Cartografía personal. Valladolid: Cuatro. Ediciones.

Benet, J. (1998). Herrumbrosas lanzas. Madrid: Santillana (Alfaguara).

Benet, J. (1998). Trece fábulas y media y Fábula decimocuarta. Madrid: Santillana (Alfaguara). (J. Machín Lucas y J. Tentinger (Trad.) (2010). An Original Translation of Trece Fábulas Y Media Y Fábula Decimocuarta. Barcelona: PPU).

Benet, J. (1999). La inspiración y el estilo. C. Martín Gaite (Intr.). Madrid: Alfaguara.

Benson, K. (1989). Razón y espíritu. Análisis de la dualidad subyacente en el discurso narrativo de Juan Benet. Stockholm: Stockholms Universitet, Romanska Institutionen.
Benson, K. (2004). Fenomenología del enigma. Juan Benet y el pensamiento literario postestructuralista. Amsterdam-New York, NY: Rodopi.

Cabrera, V. (1983). Juan Benet. Boston, Massachusetts: G. K. Hall \& Company (Twayne's World Authors Series).

Compitello, M. A. (1998). Juan Benet: camino al final de la modernidad. La Página, 30, pp. 57-68.

Da Cunha, E. (1902). Os Sertões. Brasil: Todolivro Distribuidora Ltda. Edición de 2009.

De Azúa, F. (1986). El texto invisible. Juan Benet: Un viaje de invierno. En K. M. Vernon (Ed.), Juan Benet (pp. 147-157). Madrid: Taurus.

García Pérez, F. (1997). Una meditación sobre Juan Benet. Madrid: Santillana (Alfaguara).

Genette, G. (1997). Palimpsests: Literature in the Second Degree. Ch. Newman and C. Doubinsky (Trans.), G. Prince (Fore.). Lincoln, Ne \& London: University of Nebraska Press.

Gullón, R. (1973). Una región laberíntica que bien pudiera llamarse España. Ínsula, 319, 2 y 10.

Hassan, I. H. (1987). The Posmodern Turn: Essays in Posmodern Theory and Culture. Columbus: Ohio State University Press.

Herzberger, D. K. (1976). The Novelistic World of Juan Benet. Clear Creek, IN: The American Hispanist.

Jameson, F. (1991). Posmodernism, or, The Cultural Logic of Late Capitalism. Durham: Duke University Press.

Jenofonte. (1993). Anábasis. La expedición de los Diez Mil. J. L. Vidal (Intr.), Á. Sánchez-Rivero (Trad.). Barcelona: Planeta.

Jenofonte. (2009). Anábasis. C. Varias (Ed. y Trad.). Madrid: Cátedra.

Kristeva, J. (1974). El texto de la novela. J. Llovet (Trad.). Barcelona: Lumen, 1981.

Lipovetsky, G. (2010). La era del vacío. Barcelona: Anagrama.

Lyotard, J. F. (1993). The Posmodern Condition. G. Bennington and B. Massumi (Trans). Minneapolis: University of Minnesota Press.

Machín Lucas, J. (2001). Juan Benet al trasluz: palimpsestos subversivos en Región. Cuadernos hispanoamericanos, 609, 19-28. ((2007). Region jako palimpsest. B. Jaroszuk (Trad.). Literatura na świecie, 426-427 (1-2), 56-65.

Machín Lucas, J. (2009). El primer Juan Benet (1965-1972): La forja de un estilo novelístico. Saarbrücken: VDM Verlag.

Machín Lucas, J. (2015). Filosofía, intertextualidad y posmodernismo: la influencia de Friedrich Nietzsche en la obra novelística y en la ensayística de Juan Benet. Tropelías: Revista de Teoría de la Literatura y Literatura Comparada, 23, 332-356. file:///H:/Documents \%20and\%20Settings/Antonio $\% 20$ Mach\%C3\%ADn/Mis\%20documentos/Downloads/6632241-1-PB.pdf 
Machín Lucas, J. (Septiembre 2015). Los palimpsestos de Jenofonte, de la mística y de Nietzsche en la narrativa de Juan Benet. Ínsula, 825 (año LXX), 8-11.

Margenot III, J. B. (1991). Zonas y sombras: Aproximaciones a Región de Juan Benet. Madrid: Pliegos.

Minardi, A. (2010). Las tramas de la historia entre la memoria, la utopía y la guerra: Herrumbrosas lanzas de Juan Benet y El laberinto mágico de Max Aub. En P. Civil y Fr. Crémoux (Eds.). Actas del XVI Congreso de la Asociación Internacional de Hispanistas. Nuevos caminos del hispanismo... 6. Historia y política (pp. 192-201). Madrid y Frankfurt am Main: Iberoamericana Vervuert.

Minardi, A. (2006). Hacer la Historia: el sentido de práctica discursiva en Qué fue la guerra civil, de Juan Benet. La construcción del intelectual después de Franco. Espéculo, 32. www.ucm.es/info/especulo/numero32/hacerhis.html

Minardi, A. (2012). Historia, memoria, discurso. Variaciones sobre algunos ensayos benetianos, Madrid: Pliegos.

Minardi, A. (2014). Ideología, mito y ley: tres axiomas para la presencia de Numa en la obra de Juan Benet. La nueva literatura hispánica (LNLH), 17, 119-141.

Nietzsche, F. (2009). El nacimiento de la tragedia o helenismo y pesimismo. G. Cano (Trad. y notas). En G. Cano (Intr.). Nietzsche (pp. 32-185). Vol. I. Madrid: Gredos.

Nietzsche, F. (2009). Así habló Zaratustra. Un libro para todos y para nadie. J. R. Hernández Arias (Trad. y notas). Nietzsche (pp. 11-380). Vol. II. Madrid: Gredos.

Pérez, J. (1984). The Rhetoric of Ambiguity. En R. C. Manteiga, D. K. Herzberger, and M. A. Compitello (Eds.). J. Benet (Fore.). Critical Approaches to the Writings of Juan Benet (pp. 1826). Hanover and London: published for University of Rhode Island by University Press of New England. 